\title{
From human settlement region to bird dominated grassland: Avian diversity in the Padampur grassland of Chitwan National Park, Nepal
}

\author{
Bed Khadka ${ }^{1}$, Abhinaya Pathak ${ }^{1}$, Jennifer Wilson ${ }^{2}$, Prashamsa Paudel ${ }^{3}$, Paras Acharya ${ }^{3}$, \\ Ashok Ram ${ }^{1}$, and Lokendra Adhikari ${ }^{1}$ \\ ${ }^{1}$ Ministry of Forest and Environment, Nepal \\ ${ }^{2}$ National Dong Hwa University \\ ${ }^{3}$ Tribhuvan University
}

May 12, 2021

\begin{abstract}
A Mosaics provide productive ecosystems that include foraging opportunities, breeding grounds, and protection for birds, particularly within mosaics of grassland, wetland, and savanna habitats. This study explored the status of species diversity, richness, and seasonal population rate of avian species within the mosaics of the Padampur grassland of Chitwan National Park (CNP), Nepal. Point count surveys were performed in 10 randomly selected plots by walking transects or riding on elephant back during the rainy season. A total of 118 bird species and 4905 individual birds belonging to 43 families was recorded. Surveys and regression analysis revealed species preferred diverse ecotone habitats interspersed with mosaics of tallgrass prairie, shrubby grassland, savanna and marshy grassland. Regression models also revealed occupancy rates were relatively consistent across seasons, however, months within the rainy and the summer season were lower than autumn and winter. Rarefaction curves showed sampling efforts of approximately 10 months to produce accurate estimates of species richness. Although the diversity indices resulted in insignificant differences between the plots, the CNP appears to provide preferred grassland habitat to bird species all year round. This study suggests conservation efforts to consider these survey methods and estimates when implementing initiatives. This paper recommends concerned authorities to prioritize and give continuity to bird conservation, including grassland management alongside the wetlands within the CNP.
\end{abstract}

\section{Hosted file}

Padampur_Grassland_Bird_Nepal_2021.docx available at https://authorea.com/users/413306/ articles/521683-from-human-settlement-region-to-bird-dominated-grassland-aviandiversity-in-the-padampur-grassland-of-chitwan-national-park-nepal 